This article can be cited before page numbers have been issued, to do this please use: L. Lomba Eraso, K. Afarinkia and V. Vinader, Org. Biomol. Chem., 2019, DOI: 10.1039/C9OB00630C.

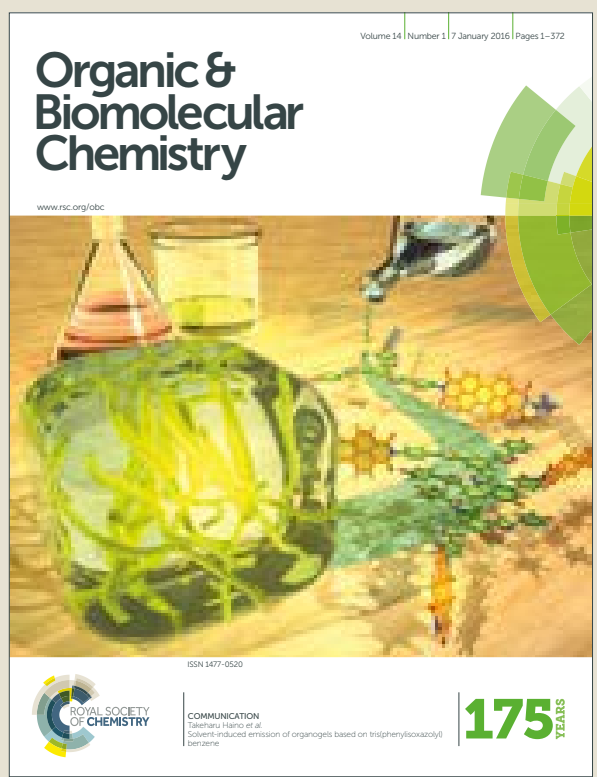

This is an Accepted Manuscript, which has been through the Royal Society of Chemistry peer review process and has been accepted for publication.

Accepted Manuscripts are published online shortly after acceptance, before technical editing, formatting and proof reading. Using this free service, authors can make their results available to the community, in citable form, before we publish the edited article. We will replace this Accepted Manuscript with the edited and formatted Advance Article as soon as it is available.

You can find more information about Accepted Manuscripts in the author guidelines.

Please note that technical editing may introduce minor changes to the text and/or graphics, which may alter content. The journal's standard Terms \& Conditions and the ethical guidelines, outlined in our author and reviewer resource centre, still apply. In no event shall the Royal Society of Chemistry be held responsible for any errors or omissions in this Accepted Manuscript or any consequences arising from the use of any information it contains. 


\section{A New Route to Tricyclane Sesquiterpenoids: Total Synthesis of $\alpha$ - Ekasantalic acid}

Received 00th January 20xx Accepted 00th January 20xx

DOI: $10.1039 / \times 0 x \times 00000 x$

\section{Lomba, ${ }^{a}$ K. Afarinkia, ${ }^{b}$ and V. Vinader ${ }^{b}$}

Chemical manipulation of the cycloadduct of citraconic anhydride and cyclopentadiene enables a new synthetic route to tricyclane sesquiterpenoids. This methodology is applied to the first total synthesis of $\alpha$-ekasantalic acid.

www.rsc.org/

traditional medicine. ${ }^{24-26}$ More recently, individual molecules

\section{Introduction}

Tricyclane sesquiterpenoids (Figure 1) are a family of nearly 100 natural products isolated from plant sources. The principle characteristic feature of this natural product family is the presence of a tricyclo[2.2.1.0 2,6$]$ heptane (tricyclane) ring within their structure. $\alpha$-Santalene, $1,^{1-3}$ and its analogues, e.g. $2-4,^{4-7}$ represent the most common skeleton in this family, although other skeletons, as exemplified by cyclosinularane, $\mathbf{5 , 8}$ cycloseychellene, $\mathbf{6},{ }^{9}$ and cyclomyltaylan-5 $\alpha$-ol, 7, ${ }^{10,11}$ are also reported. A handful of molecules in this family contain a fourth ring leading to compact and complex skeletons comprising of several quaternary carbon atoms. These include longicyclene, $\mathbf{8},{ }^{12,13}$ and it's analogues $\mathbf{9},{ }^{14}$ and $\mathbf{1 0} ;^{12,13}$ cyclosativene, 11, ${ }^{15-21}$ cyclocopacamphene, $\mathbf{1 2}, 19,22$ and dendronobilin $\mathrm{N}, \mathbf{1 3} .^{23}$

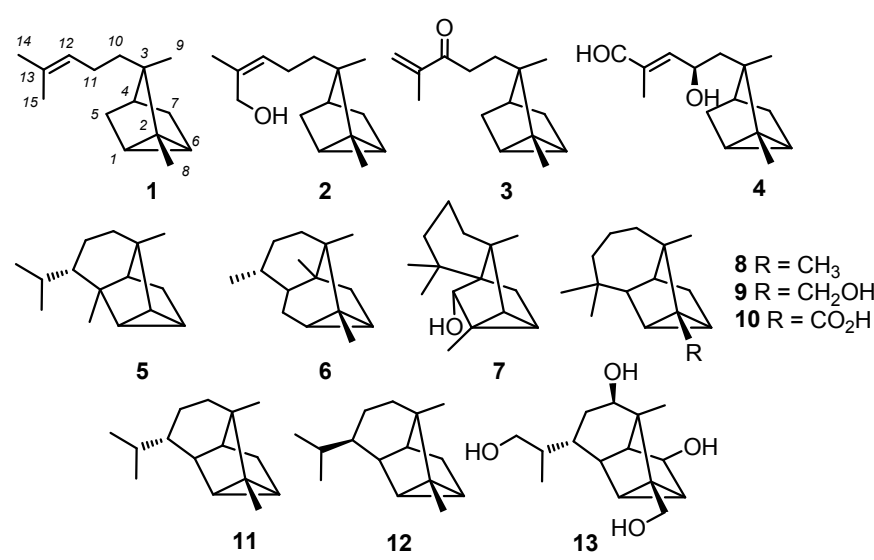

Figure 1 Tricyclane sesquiterpenoid family and related compounds.

Traditionally, tricyclane sesquiterpenoids' main use has been in the perfumery and flavouring industries, although many plant extracts that do contain them have also been used in

\footnotetext{
a. Campus Universitario de Villanueva de Gállego (Zaragoza), 50.830 Villanueva de Gállego (Zaragoza), Spain

b. Institute of Cancer Therapeutics, University of Bradford, Bradford BD7 1DP, UK. c. Electronic Supplementary Information (ESI) available: For detailed experimental procedure and characterisation of all compounds, see: DOI: 10.1039/x0xx00000x
} with antifungal, antibacterial and antitumor properties are reported in the literature. For example, $\alpha$-santalol, 2 , binds to tubulin and cause $\mathrm{G} 2 / \mathrm{M}$ cell cycle arrest in a panel of head and neck cancer cell lines ${ }^{5}$ and HL-60 leukaemia cells; ${ }^{4}$ inhibits migration of MCF-7 and MDA-MB-231 breast cancer cells by targeting the $ß$-catenin pathway; ${ }^{27}$ and is an antagonist of $D_{2}$ and $5-\mathrm{HT}_{2 \mathrm{~A}}$ receptors. ${ }^{28}$ Compound $\mathbf{2}$ is also shown to be mildly active against Helicobacter pylori ${ }^{6}$ whilst compound $\mathbf{3}$ is reported to have antimicrobial activity against the oral pathogen Porphyromonas gingivalis. ${ }^{7}$ Compound $\mathbf{4}$ is a proapoptotic cytotoxin at sub $\mu \mathrm{M}$ concentrations, ${ }^{29}$ showing selectivity for tumour cells against healthy ones; and compound 10, a metabolite of longicyclene, suppresses the SOS response induced by chemical mutagens. ${ }^{30}$

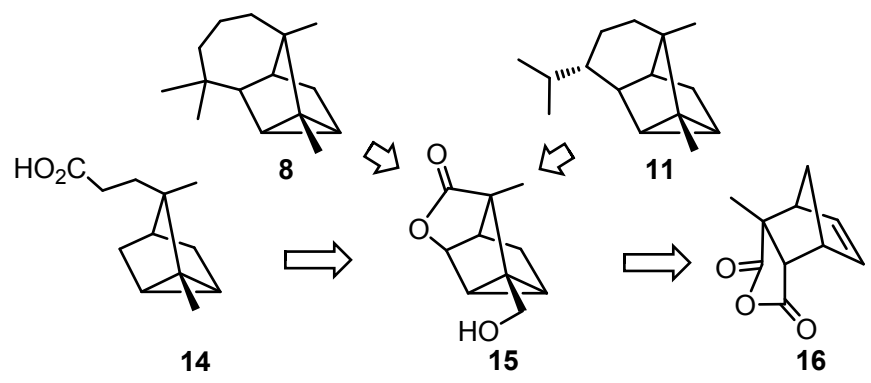

Figure 2 Proposed synthetic route to tricyclic $\alpha$-ekasantalic acid, 14, and to tetracyclic sesquiterpenoids.

Further understanding of the mode of action of this rare class of molecules, as well as their development as potential therapeutics, is severely hampered by the lack of robust and general synthetic routes to prepare them. Although there are a number of efficient routes to the synthesis of tricylances, ${ }^{31-34}$ few have found application in total synthesis. In view of the potential biological interest in this family of compounds, we set out to develop a general and divergent synthetic route to them and in particular to synthesise versatile intermediates that can be used in the preparation of different targets in this family, including functionalised analogues of $\alpha$-santalene and those with a fourth ring such as longicyclene, 8 and 
cyclosativene, 11 . Here we report the first total synthesis of $\alpha$ ekasantalic acid, 14,35 a constituent of East Indian sandalwood oil, ${ }^{36,37}$ also known as tricycloekasantalic acid in some literature and preparation of a number of key intermediates, such as 15, which can be used both in preparation of analogues as well as in total syntheses of other members of this family (Figure 2).

\section{Results and discussion}

Commercially available citraconic anhydride underwent an efficient Diels-Alder cycloaddition with cyclopentadiene to afford exclusively the endo cycloadduct 16. Treatment of cycloadduct $\mathbf{1 6}$ with sodium isopropoxide, selectively afforded sodium carboxylate salt $\mathbf{1 7}$ (Figure $\mathbf{3}$ ). The regioselectivity of the acid anhydride ring opening is most likely due to steric factors. The bulky isopropoxide anion avoids attacking the carboxyl function adjacent to the quaternary carbon atom due to the methyl substituent. Furthermore, under these basic reaction conditions, the ester group is epimerised to the less sterically encumbered and hence more thermodynamically favoured exo position.
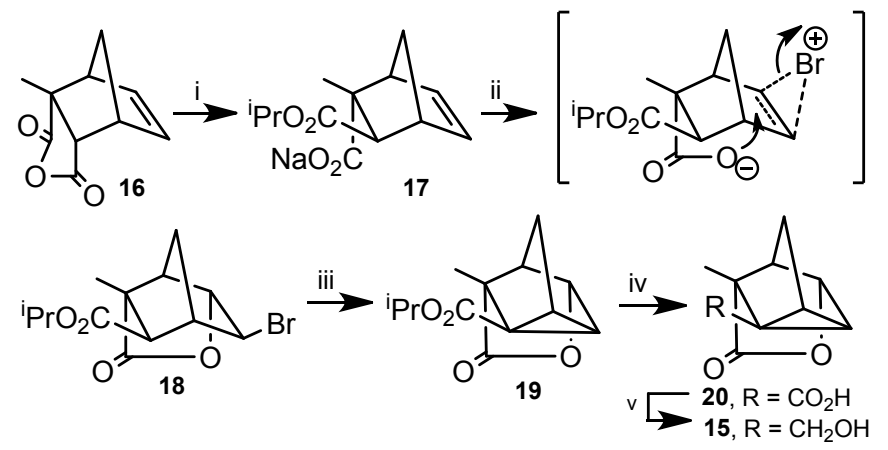

i) i-PrONa, i-PrOH, rt, $15 \mathrm{~h}, 92 \%$; ii) $\mathrm{Br}_{2}, \mathrm{H}_{2} \mathrm{O}, 98 \%$; iii) tert-BuOK, THF, $15 \mathrm{~h}, 65 \%$; iv) $15 \%$ Aq. $\mathrm{HCl}$, reflux, $96 \%$; v) $\mathrm{BH}_{3} . \mathrm{THF}, \mathrm{CH}_{2} \mathrm{Cl}_{2}$, rt, $5 \mathrm{~h}, 89 \%$

Figure 3 Preparation of key intermediate $\mathbf{1 5}$

Treatment of $\mathbf{1 7}$ with bromine in water affords bromide $\mathbf{1 8}$. Reaction proceeds via formation of a bromonium cation from the less sterically hindered face of the alkene, followed by backside attack of the nucleophilic carboxylate. Treatment of 18 with potassium tert-butoxide in tetrahydrofuran resulted in enolisation of the noncyclic ester, followed by intramolecular cyclisation and elimination of potassium bromide to give 19. We have previously shown that similar carbanion-initiated cyclisations are a facile route to tricyclanes. ${ }^{31}$

It was possible to selectively hydrolyse the non-cyclic ester in 19 under acidic conditions to obtain 20. Presumably, under acidic conditions, any hydrolysis of the cyclic ester will be followed by facile re-esterification, since the hydroxyl and carboxylic groups are spatially close. Reduction of the carboxylic acid function in $\mathbf{2 0}$ with borane afforded the key intermediate alcohol $\mathbf{1 5}$ in multigram quantities in 6 steps and $50 \%$ overall yield (Figure 3 ).
Next, alcohol 15 was transformed to iodide $\mathbf{2 1}$ which was then treated with lithium aluminium hydrideOto leffieientipoaffora bisalcohol 22 (Figure 4). In addition to compound 22, hydride reduction of $\mathbf{2 1}$ also afforded compound $\mathbf{2 3}$ as a minor byproduct ( $2 \%$ isolated) which is obtained by conjugate addition of a hydride at $\mathrm{C}-1$ to open the cyclopropane ring. Although the yield of this by product is too small for it to be a synthetically useful step, the production of $\mathbf{2 3}$ is interesting since chain extension at C10 would lead to $\beta$-santalene skeleton.

Our next task was to selectively manipulate one of two hydroxyl groups in compound 22. However, all our attempts at selective protection of one of two hydroxyl groups in compound $\mathbf{2 2}$ were unsuccessful. These included treatment with Boc anhydride, benzoyl chloide and pivaloyl chloide, TBDMSCI, TBDMS-imidazole, and TBDPSCI. Presumably, this is because the primary neopentyl primary alcohol and the secondary alcohol functions have similar steric demand. In order to chemically distinguish the two hydroxyl groups, we converted the bisalcohol $\mathbf{2 2}$ to compound $\mathbf{2 4}$ by Swern oxidation, with the knowledge that aldehydes react more efficiently than ketones in Wittig type reactions. Gratifyingly, we found that the aldehyde function in compound 24 selectively undergoes Wittig reactions. Thus, treatment of compound $\mathbf{2 4}$ with the corresponding Wittig reagent, followed by hydrogenation of the resulting alkene afforded 5-keto- $\alpha$ ekasantalic acid ethyl ester, 25. The reduction of the 5-keto group was achieved via the transformation to the thione 26, using Lawesson's reagent, followed by reduction using $\left(\mathrm{NiCl}_{2} / \mathrm{NaBH}_{4}\right)$ to afford 27 . The hydrolysis of $\mathbf{2 7}$ produced $\alpha-$ ekasantalic acid, 14 (Figure 4). This represents the first total synthesis of $( \pm)$ - $\alpha$-ekasantalic acid, 14 . Furthermore, compound $\mathbf{2 7}$ is a known precursor in the total synthesis of $\alpha$ santalene, ${ }^{38}$ therefore this synthetic route also represents a formal synthesis of $\mathbf{1}$.

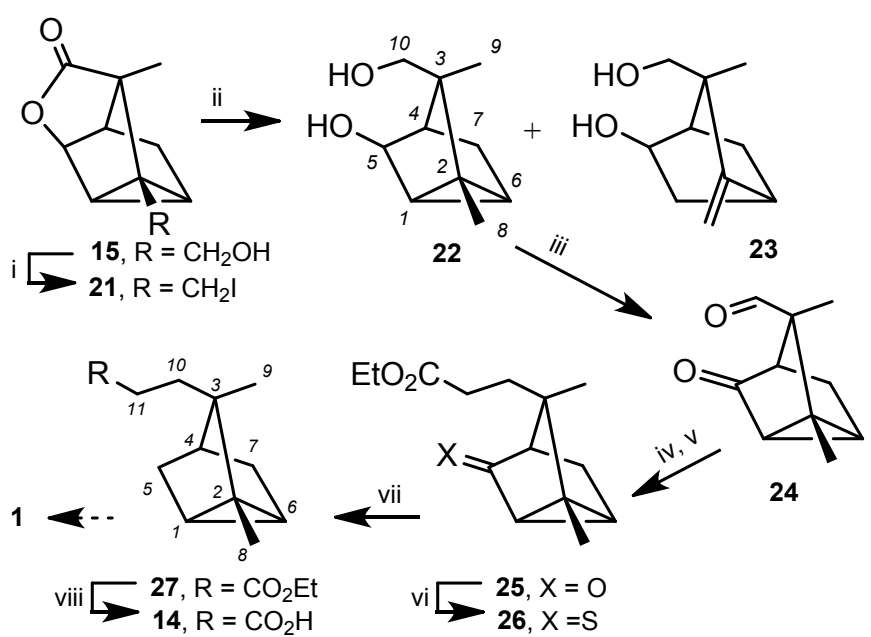

i) $\mathrm{PPh}_{3}, \mathrm{I}_{2}$, Imidazole, $83 \%$; ii) $\mathrm{LiAlH}_{4}$, THF, reflux, $84 \%$; iii) DMSO, $\mathrm{Et}_{3} \mathrm{~N},(\mathrm{COCl})_{2}$, $\mathrm{CH}_{2} \mathrm{Cl}_{2}, 95 \%$; iv) $\mathrm{Ph}_{3} \mathrm{P}=\mathrm{CHCO}_{2} \mathrm{Et}$, THF, $22 \mathrm{~h}, 97 \%$; v) $\mathrm{H}_{2}$, EtOAc, (10\%)Pd/C, $100 \%$; vi) Lawesson's reagent, toluene reflux, $24 \mathrm{~h}, 80 \%$; vii) $\mathrm{NiCl}_{2}$, EtOH, $\mathrm{NaBH}_{4}$, reflux, $1 \mathrm{~h}$, $75 \%$; viii) Aq. $\mathrm{NaOH}(1 \mathrm{M}), \mathrm{THF}, 95 \%$; viii) $\mathrm{Ph}_{3} \mathrm{P}=\mathrm{CHCO} \mathrm{Pr}, \mathrm{THF}, 35 \mathrm{~h}, 96 \%$.

Figure 4 Preparation of ( \pm )- $\alpha$-ekasantalic acid, 14. 


\section{Conclusions}

In summary, we report the first total synthesis of $( \pm)-\alpha-$ ekasantalic acid, an unusual sesquiterpenoid containing a tricyclo[2.2.1.0 2,6]heptane (tricyclane) ring. The methodology we have developed, uses intermediates in which C5 bears functionality meaning that it can be utilised in the construction of a fourth ring, as present in, for example, longicyclene, $\mathbf{8}$ and cyclosativene, 11. Further work towards the total synthesis of these natural products is currently underway in our group. In addition, we are also investigating the biological activity of these compounds and their analogues and will report our results in due course.

\section{Experimental}

Synthetic procedures and full characterisation data are provided in the suporting information.

\section{Conflicts of interest}

There are no conflicts of interest to declare.

\section{Acknowledgements}

We thank Spanish Ministry of Education, Culture and Sport grant number TME2011-00267 (LL) for financial support

\section{Notes and references}

1 Corey, E. J.; Chow, S. W.; Scherrer, R. A. J. Am. Chem. Soc. 1957, 79, 5773.

2 Schlosser, M.; Zhong, G. F. Tetrahedron Lett. 1993, 34, 54415444.

3 Bastiaansen, P. M. F. M.; Wijnberg, J. B. P. A.; de Groot, A. J. Org. Chem. 1996, 61, 4955-4958.

4 Lee, B.; Bohmann, J.; Reeves, T.; Levenson, C.; Risinger, A. L. J. Nat. Prod. 2015, 78, 1357-1362.

5 Matsuo, Y.; Mimaki, Y. Phytochemistry 2012, 77, 304-311. Erratum in Phytochemistry 2012, 81, 175.

6 Ochi, T.; Shibata, H; Higuti, T.; Kodama, K.H.; Kusumi, T.; Takaishi, Y. J. Nat. Prod. 2005, 68, 819-824.

7 Kubo, M.; Nishikawa, Y.; Harada, K.; Oda, M.; Huang, J.M.; Domon, H.; Terao, Y.; Fukuyama, Y. J. Nat. Prod. 2015, 78, 1466-1469.

8 Yasumoto, M.; Mada, K.; Ooi, T.; Kusumi, T. J. Nat. Prod. 2000, 63, 1534-1536.

9 Welch, S. C.; Gruber, J. M.; Morrison, P. A. J. Org. Chem. 1985, 50, 2676-2681.

10 Hagiwara. H.; Sakai, H.; Uchiyama, T.; Ito Y, Morita, N.; Hoshi, T.; Suzuki, T.; Ando, M. J. Chem. Soc. Perkin Trans. 1, 2002, 583.

11 Sakai, H.; Hagiwara. H.; Ito, Y.; Hoshi, T.; Suzuki, T.; Ando, M. Tetrahedron Lett. 1999, 40, 2965.

12 Welch, S. C.; Walters, R. L. J. Org. Chem. 1974, 39, 2665.

13 Kelly, T. R. Tetrahedron Lett. 1973, 437.

14 Shieh, B.; lizuka, Y.; Matsubara, Y. Agr. Biol. Chem. Tokyo 1981, 45, 1497-1499.

15 Heissler, D.; Riehl, J. J. Tetrahedron Lett. 1980, 21, 4707

16 Baldwin S. W.; Tomesch J. C. J. Org. Chem. 1980, 45, 1455.
17 Heissler, D.; Jung, F.; Vevert, J. P.; Riehl, J. J Tetrahedron Lett. 1976, 4879.

DOI: 10.1039/C9OB00630C

18 Hagiwara, H.; Miyashita, M.; Uda, H.; Yoshikoshi, A. Bull. Chem. Soc. Jap. 1975, 48, 3723.

19 Piers, E.; Geraghty, M. B.; Smillie, R. D.; Soucy, M. Can. J. Chem. 1975, 53, 2849.

20 Baldwin S. W.; Tomesch J. C. Tetrahedron Lett. 1975, 1055.

21 McMurry, J. E. Tetrahedron Lett. 1969, 55.

22 Piers, E.; Britton R. W., Keziere R. J.; Smillie, R. D. Can. J. Chem. 1971, 49, 2623.

23 Sakata, K.; Mirazawa, M. J. Agric. Food Chem. 2010, 58, 9001-9005.

24 Santha, S.; Dwivedi, C. Anticancer Res. 2015, 35, 3137-3145.

25 Dickinson, S.E.; Olson, E.R.; Levenson, C.; Janda, J.; Rusche, J.J.; Alberts, D.S.; Bowden, G.T. Arch Biochem Biophys. 2014, $558,143-152$

26 Mohankumar, A.; Shanmugam, G.; Kalaiselvi, D.; Levenson, C.; Nivitha, S.; Thiruppathi G.; Sundararaj P. RSC Adv. 2018 , 8, 33753-33774.

27 Bommareddy, A.; Knapp, K.; Nemeth, A.; Steigerwalt, J.; Landis, T.; Vanwert, A.L.; Gorijavolu H.P.; Dwivedi, C. Anticancer Res. 2018, 38, 4475-4480.

28 Okugawa, H.; Ueda, R.; Matsumoto, K.; Kawanishi, K.; Kato, K. Phytomedicine 2000, 7, 417-422.

29 Matsuo, Y.; Mimaki, Y. Phytochemistry, 2012, 77, 304-311.

30 Wang, L.; Zhang, C. F.; Wang, Z. T.; Zhang, M.; Xu, L. S. J. Asian Nat. Prod. Res. 2009, 11, 903-911.

31 Afarinkia, K.; Mahmood, F. Tetrahedron Lett., 2000, 41, 1287-1290.

32 Fabris, F.; Pellizzaro, L.; Zonta, C.; De Lucchi, O. Eur. J. Org. Chem. 2007, 283-291.

33 Alnajjar, M. S.; Kuivila, H. G. J. Org. Chem. 1981, 46, 10531057.

34 Roberts, J. D.; Lee, C. C.; Saunders, W. H., Jr. J. Am. Chem. Soc. 1955, 77, 3034-3037.

35 Rani Bai, P.; Kamat, S. Y.; Ghatge, B. B.; Chakravart, K. K.; Baitachary, S. C. Tetrahedron, 1965, 21, 629 - 635.

36 Buchbauer, G.; Maerz, M. A.; Ehrmann-Falkenau, E. Sci. Pharm. 1979, 47, 319-327.

37 Demole, E.; Demole, C.; Enggist, P. Helv. Chim. Acta, 1976, 59, 737-747.

38 Christenson, P. A.; Willis, B. J. J. Org. Chem. 1980, 45, 30683072. 